\title{
Preliminary step towards comparing large scale features in surface wind field between ERA-Interim re-analysis and a higher resolution simulation
}

\author{
A. Boilley ${ }^{1}$, T. Ranchin ${ }^{1}$, and A. Ghennioui ${ }^{2}$ \\ ${ }^{1}$ MINES ParisTech, O.I.E. - Centre Observation, Impacts, Energie, CS 10207 rue Claude Daunesse, \\ 06904 Sophia Antipolis Cedex, France \\ ${ }^{2}$ Institut de Recherche en Energie Solaire et Energies Nouvelles, Rabat, Morocco
}

Correspondence to: A. Boilley (alexandre.boilley@mines-paristech.fr)

Received: 30 November 2012 - Revised: 26 August 2013 - Accepted: 15 September 2013 - Published: 11 October 2013

\begin{abstract}
The weather research and forecasting model (WRF) is initialized with ERA-Interim re-analysis to produce a higher resolution dataset over a one month period. WRF is supposed to introduce small scale information and maintain the mean large scale features. A detailed spectral analysis is performed to verify this statement. It reveals that consistency in large-scale features is not achieved for wavelengths greater than or equal to $6^{\circ}$ even with the activation of spectral nudging.
\end{abstract}

\section{Introduction}

Morocco has engaged itself in an appraisal of the wind energy resources. The first step is a wind atlas that will depict the mean wind speed at $100 \mathrm{~m}$ height above land and coastal areas. The wind atlas is created by averaging instantaneous wind fields during several years.

High resolution wind fields needed for the atlas are currently unavailable. The dynamical downscaling method is an approach to create them. Dynamical downscaling consists in initializing a numerical meteorological model with a coarse resolution analysis and run the model at a higher resolution over the area of interest. Most of the time a re-analysis field is used (Castro et al., 2005; Heikkilä et al., 2011) since it is considered as the best field a numerical model can produce at the resolution of the re-analysis. In our case, no local measurements are assimilated in the high resolution model.

Traditionally the atlas is compared to several independent measurements to estimate its reliability. It determines its ability to represent some particular local flows but do not validate the atlas over the entire region. To overcome this challenge, one may think of comparing the re-analysis and the high resolution fields once remapped at the coarse resolution. Ideally, the difference should be small and the consistency of large scale features between both data sets should be large. This is particularly true for variables independent from orographic effects.

This paper presents a method to perform such a comparison and to study the amount of large scale patterns from re-analysis maintained by a numerical downscaling process with and without spectral nudging. It aims at evaluating the magnitude of the consistency error between a re-analysis dataset and a higher resolution simulation for wind speed at $100 \mathrm{~m}$. In the case when the consistency error is high, a further effort should be carried out to modify the large scale features of the wind atlas through data fusion for example (Fichaux et al., 2005).

\section{Method}

\subsection{Numerical simulation setup}

We use the European Centre for Medium-range Weather Forecast (ECMWF) ERA-Interim re-analysis (Dee et al., 2011) as input and the Weather Research and Forecasting (WRF, Skamarock et al., 2008) as high resolution model. WRF is initialized once with ERA-Interim and the boundary conditions are then updated each $6 \mathrm{~h}$ with ERA-Interim during the month of January 2004; output files are produced each hour. The simulation is carried out on a domain of $256 \times 256$ 


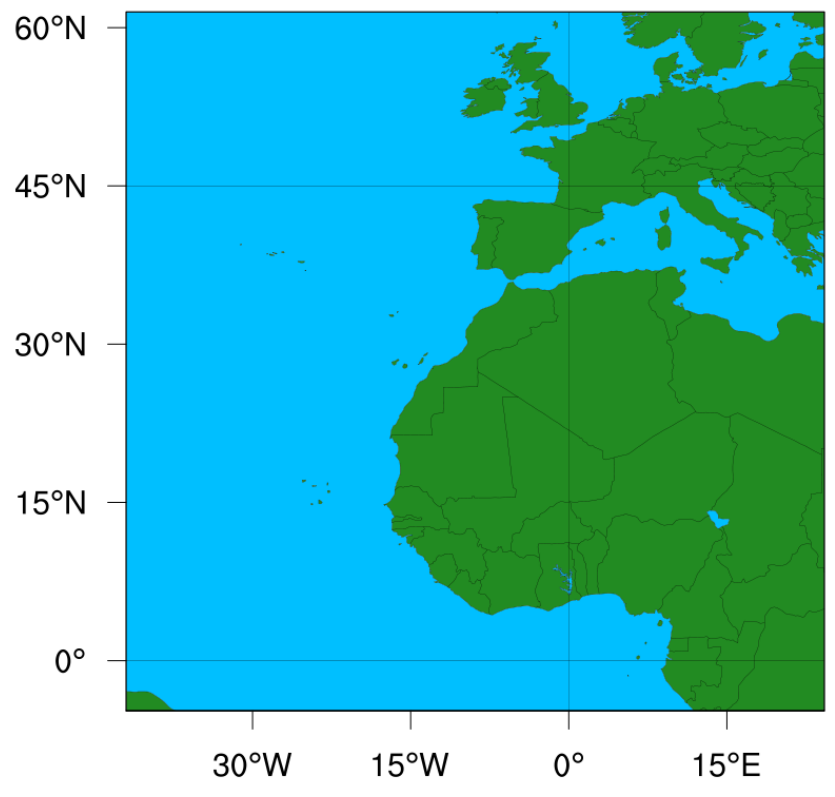

Figure 1. WRF simulation domain at $0.25^{\circ}$ resolution.

nodes at $0.25^{\circ}$ resolution containing Europe and a part of the African continent (Fig. 1). We designed 40 vertical levels to fit the 40 first vertical levels of ERA-Interim at initial time. The domain of study can represent the coarser domain for a dynamical downscaling method to produce a wind atlas over Morocco. No higher resolution domains are nested in this paper.

The fully compressible non-hydrostatic equations are integrated on a 60 s time step using the 3rd order Runge Kutta scheme. Land and lakes surface temperature and moisture as well as snow cover and frozen soil physics are computed by the Noah Land Surface Model (Chen et al., 1996) in four layers every time steps. The sea-surface temperature and the deep soil layer are updated every $6 \mathrm{~h}$ with ERA-Interim data. Cumulus are parameterized using the Kain-Fritsch scheme (Kain and Fritsch, 1990) and since the final goal is to obtain a high resolution atlas a sophisticated 6-class microphysics scheme (Hong and Lim, 2006) is used. The other parameters are set to the default value.

A simulation (NODA) is run without data assimilation. The interior part of the domain, far from the lateral boundary conditions is left alone and only the physical and dynamical processes take place. This is the worst case configuration; the low predictability of the atmosphere implies an expected low consistency in that case. A second simulation (SPECNUD) is conducted with spectral nudging turned on above the 10th vertical level (approximately $1200 \mathrm{~m}$ a.g.l.). The nudging coefficient linearly increases to full strength $\left(5.10^{-4} \mathrm{~s}^{-1}\right)$ for the next 3 vertical levels. The wave number considered for nudging is set to 3 in each directions corresponding to a resolution of $21^{\circ}$ approximately. The configuration with spectral nudging activated should lead to a better agreement between WRF and ERA-Interim large scales and could be used for the computation of a wind atlas.

\subsection{Consistency error}

ERA-Interim dataset is the reference field in the following. In order to avoid the introduction of discrepancies in the reference through the re-sampling and interpolation processes (Wald et al., 1997), the ERA-Interim wind fields are only re-sampled from the $0.75^{\circ}$ original grid points onto a $0.25^{\circ}$ grid, each $6 \mathrm{~h}$. The WRF high resolution fields are then interpolated horizontally and vertically on the same grid. Even if the two fields are gridded the same way, the information scale contained in each field is different. Obviously, the WRF simulation exhibits more fine structures than ERA-Interim. Due to the resolution difference and since the simulation NODA is run freely, a direct comparison between reference and simulations results cannot be considered.

The physical processes scale represented by a gridded domain can be at most twice the resolution of the grid as stated by the Nyquist-Shannon sampling theorem. Hence ERAInterim, which resolution is $0.75^{\circ}$, represents processes at most $1.5^{\circ}$ resolution. A theoretical anti-aliasing low-pass filter $\left(H_{\text {theo }}\right)$ has then been designed to remove the information contained in scales less than $1.5^{\circ}$ (twice the resolution of ERA-Interim) from the WRF simulations, noted RUN in the following equations. $H_{\text {theo }}$ is a sinus cardinal function in the spatial domain apodized with a Blackman function (Blackman and Tukey, 1958). By construction, the remapped re-analysis noted ANA in the following equations, does not contain information at scales less than $1.5^{\circ}$. The difference between the one month mean analysis $\overline{\mathrm{ANA}}$ and simulation $\overline{\mathrm{RUN}}$ convoluted to the theoretical filter is called the consistency error (CE) and is defined as follows:

$\mathrm{CE}=\overline{\mathrm{ANA}}-H_{\text {theo }} \cdot \overline{\mathrm{RUN}}$

The absolute value of monthly mean consistency error is presented in Fig. 2a for the NODA simulation and in Fig. 2b for the SPECNUD simulation. Large errors up to $5 \mathrm{~m} \mathrm{~s}^{-1}$ appear in complex terrain for the NODA simulation since the $100 \mathrm{~m}$ wind is not independent of orographic effects. Even if diminished of $25 \%$ in mean, the error remains large for the SPECNUD simulation. The error over the ocean and in coastal area is however high.

For both NODA and SPECNUD simulations the consistency error exhibits a fine scale structured field. It means that the theoretical filter did not remove enough scales from the WRF field to be coherent with the features from ERAInterim. The smaller scale theoretically represented by ERAInterim are modified by WRF.

\subsection{Can the consistency error be decreased?}

We have further investigated the change in consistency error with scale. As stated previously the theoretical filter is 


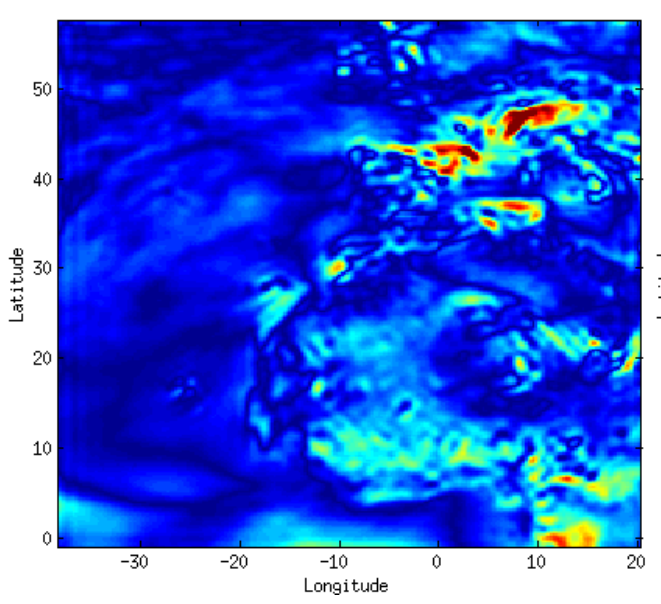

(a)

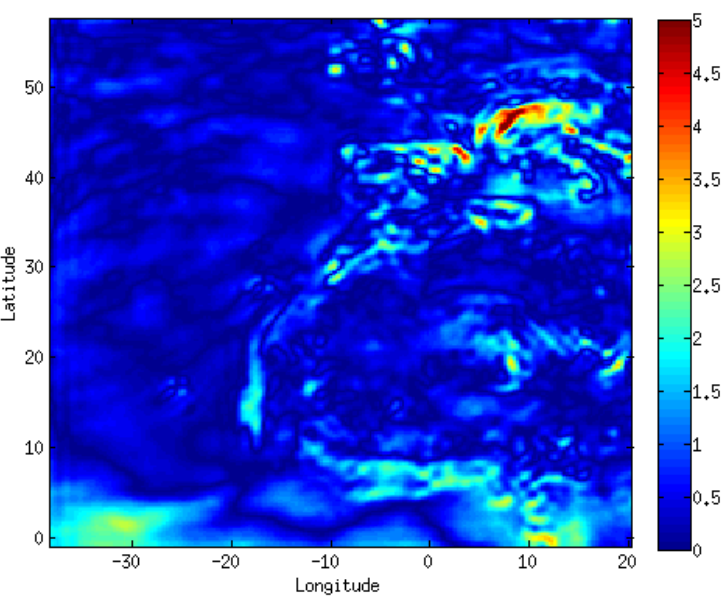

(b)

Figure 2. Absolute value of the consistency error for the monthly mean of the NODA simulation (a) and SPECNUD simulation (b) obtain with the theoretical filter.

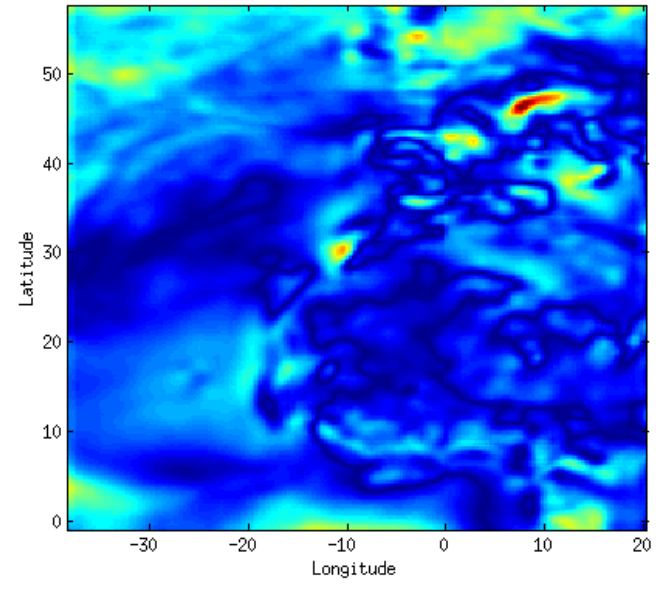

(a)

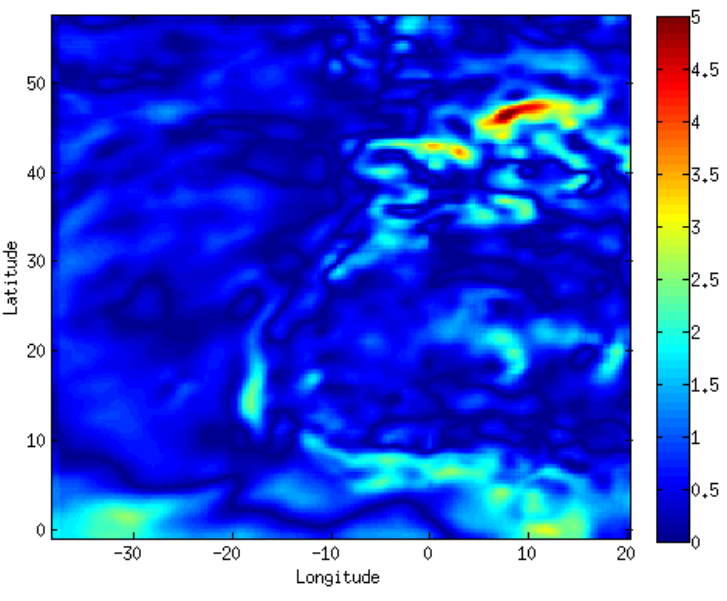

(b)

Figure 3. Absolute value of the consistency error for the monthly mean of the NODA simulation (a) and SPECNUD simulation (b) obtain with the optimal filter.

not adequate to obtain a great consistency between WRF and ERA-Interim. The objective is yet to assess the existence and the value of a threshold scale above which the error is small or acceptable. We expect the spectral nudging to modify this threshold since the WRF large scales are constrained towards large scales from ERA-Interim. A filter $H_{\mathrm{opt}}$ is designed such as to minimize the consistency. It is constructed from the Fourier transform of the auto-correlation function $(\Gamma)$ :

$S(f)=\int_{-\infty}^{\infty} \Gamma(\tau) e^{-2 j \pi f \tau} \mathrm{d} \tau$

so that $E\left[\left(H_{\mathrm{opt}} \cdot \mathrm{RUN}-\mathrm{ANA}\right)^{2}\right]$ is minimal. Assuming 2 nd order stationary processes and applying the perpendicularity theorem, it can be proven that the re-analysis auto-correlation is related to the cross-correlation:

$H_{\mathrm{opt}}=\mathrm{TF}^{-1}\left(\frac{S_{\mathrm{ANA}}}{S_{\mathrm{RUN}, \mathrm{ANA}}}\right)$

Using Eq. (1), $H_{\text {opt }}$ is applied to the one month period mean wind speed. The obtain filter provides the threshold above which the large scale structures are maintained by the high resolution model in the mean wind field and its amplitude determine the amount of information maintained.

By definition, this is the smallest consistency error that can be obtained by removing information from the high resolution simulation. The mean error magnitude is reduced by about $20 \%$ for the NODA simulation and by about $15 \%$ for 


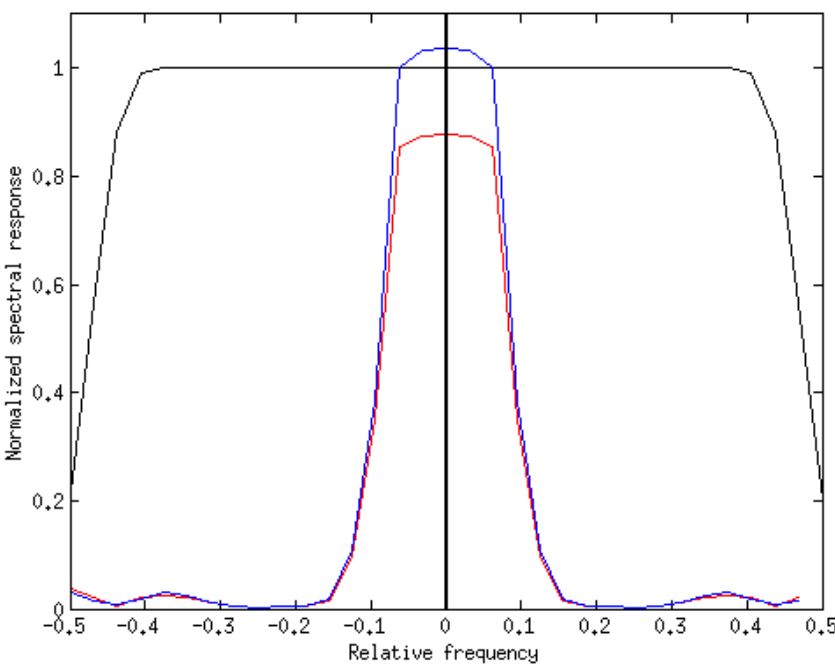

Figure 4. Latitudinal profile of the optimal filter for the one month mean of the $100 \mathrm{~m}$ wind speed plotted on relative frequency range ( 0.5 corresponds to half the sampling rate of the re-analysis) for the NODA simulation (in red) and for the SPECNUD simulation (in blue). The theoretical filter is represented as the thin black line.

the SPECNUD simulation (Fig. 3) compared to the consistency error in the theoretical case (Fig. 2). Many previously observed fine scales structures have been removed. The error is however slightly increased over ocean and reduced over flat terrain.

The obtained filter shapes are isotropic which means that there is no preferential treatment along one direction upon the other. The latitudinal profile of the optimal filter for both simulations is presented in Fig. 4 and superimposed on the transect of the theoretical filter. In Fig. 4 the frequency axis is graduated relatively to the sampling frequency of the reanalysis: a value of 0.5 corresponds to a wavelength of $1.5^{\circ}$. The optimal filters are mostly rectangular from -0.12 to 0.12 . It corresponds to a low-pass filter with a low-pass threshold of $6.25^{\circ}$; structures from ERA-Interim less than $6.25^{\circ}$ are strongly modified by the WRF model. This threshold is almost the same for both simulations.

It can be noted that the maximum spectral response of the filter is not equal to 1 . When the model is run freely the large scale mean wind speed is increasing along with the resolution. When the spectral nudging is turned on the amount of large scale structures is slightly lesser in WRF than in ERAInterim. To perfectly match the ERA-Interim large scales a smaller nudging coefficient $\left(4.10^{-4} \mathrm{~s}^{-1}\right.$ for example) should be used. Hence this comparison technique can be used to determine the best WRF nudging configuration.

Once $H_{\text {opt }}$ is obtained for the monthly mean it is applied to the WRF output every $6 \mathrm{~h}$ and the consistency error time series is computed. The time evolution of the error is presented in Fig. 5 for the month of January 2004. The time series demonstrates that the error is growing along with the

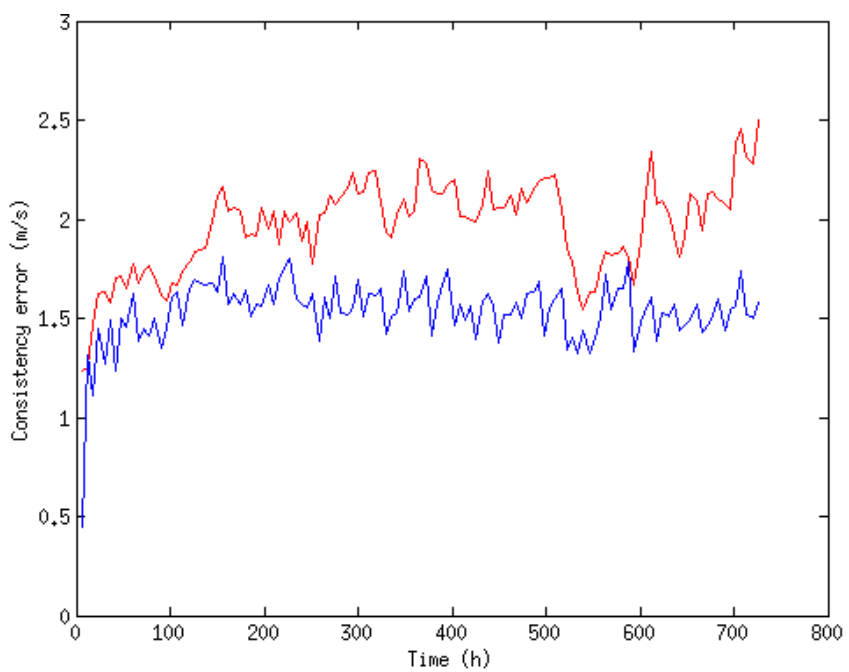

Figure 5. 6h-time series of the consistency error over the one month period for the NODA simulation in red and for the SPECNUD simulation in blue.

duration of the simulation when the model is run freely but remains quite constant when spectral nudging is turned on. It confirms that the model has to be constraint regularly towards a re-analysis to perform a long lasting wind atlas simulation. The rapid increase at the beginning of the time series corresponds to the spin-up period of the model that can be estimated to $24 \mathrm{~h}$.

\section{Conclusions}

The method presented in this paper is a possible approach to quantify the spatial representativeness of high resolution numerical model compared to re-analysis. It is able to determine the scales from re-analysis, considered as the best information, kept in the high resolution wind field. In the present study, two WRF simulations with and without data assimilation are compared to ERA-Interim re-analysis. After removing the theoretical range of information from high resolution simulations to be on the exact same theoretical range scale than re-analysis, the consistency error remains large and includes still fine scale structures. An optimal filter is then computed to minimize the consistency error. The obtained filter is a thinner low-pass filter compared to the theoretical filter. It means that WRF modifies the information up to 5 times the size of the grid cell resolution of the re-analysis. Turning on the spectral nudging does not modify this threshold but maintains the magnitude of large scale under this threshold. It leads to a higher consistency between WRF and ERA-Interim and this consistency remains stable over the one month period simulation whereas it increases without constraint.

Simulations with different spectral nudging configurations could be run to determine the effect of the nudging coefficient 
or of the wave number for example. A longer simulation is also needed to verify that the WRF model remains coherent with the re-analysis over long time periods such as years needed for a wind atlas. The difference between the NODA and SPECNUD simulations raises the question on the impact of the misrepresentation of the large scale features. Indeed the range of the large scale from re-analysis maintained in both high resolution simulations is similar. The amount is however superior over these scales when spectral nudging is activated. The obtained wind atlas (here over a one month period) is more reliable for the SPECNUD than for the NODA simulation. Would the wind atlas be even more reliable with a stronger constraint towards re-analysis?

Acknowledgements. The authors would like to acknowledge Lucien Wald for his remark about the paper and Philippe Blanc for his help in mathematics and programming. This work was achieved with the financial support of IRESEN and in collaboration with Transvalor Innovation.

Edited by: E. Batchvarova

Reviewed by: two anonymous referees

\section{References}

Blackman, R. B. and Tukey, J. W.: The measurement of power spectra, from the point of view of communications engineering, Dover Publications, 1958.

Castro, C., Pielke, R., and Leoncini, G.: Dynamical downscaling: Assessment of value retained and added using the regional atmospheric modeling system (RAMS) RID A-5015-2009, J. Geophys. Res.-Atmos., 110, D05108, doi:10.1029/2004JD004721, 2005.

Chen, F., Mitchell, K., Schaake, J., Xue, Y. K., Pan, H. L., Koren, V., Duan, Q. Y., Ek, M., and Betts, A.: Modeling of land surface evaporation by four schemes and comparison with FIFE observations, J. Geophys. Res.-Atmos., 101, 7251-7268, doi:10.1029/95JD02165, 1996.
Dee, D. P., Uppala, S. M., Simmons, A. J., Berrisford, P., Poli, P., Kobayashi, S., Andrae, U., Balmaseda, M. A., Balsamo, G., Bauer, P., Bechtold, P., Beljaars, A. C. M., van de Berg, L., Bidlot, J., Bormann, N., Delsol, C., Dragani, R., Fuentes, M., Geer, A. J., Haimberger, L., Healy, S. B., Hersbach, H., Hólm, E. V., Isaksen, L., Kållberg, P., Köhler, M., Matricardi, M., McNally, A. P., Monge-Sanz, B. M., Morcrette, J.-J., Park, B.-K., Peubey, C., de Rosnay, P., Tavolato, C., Thépaut, J.-N., and Vitart, F.: The ERA-Interim reanalysis: configuration and performance of the data assimilation system, Q. J. Roy. Meteor. Soc., 137, 553-597, doi:10.1002/qj.828, 2011.

Fichaux, N., Poglio, T., and Ranchin, T.: Mapping offshore wind resources: Synergetic potential of SAR and scatterometer data, IEEE J. Ocean. Eng., 30, 516-525, doi:10.1109/JOE.2005.857504, 2005.

Heikkilä, U., Sandvik, A., and Sorteberg, A.: Dynamical downscaling of ERA-40 in complex terrain using the WRF regional climate model, Clim. Dynam., 37, 1551-1564, doi:10.1007/s00382-010-0928-6, 2011.

Hong, S.-Y. and Lim, J.-O. J.: The WRF Single-Moment 6-Class Microphysics Scheme (WSM6), J. Korean Meteor. Soc., 42, 129-151, 2006.

Kain, J. and Fritsch, J.: A One-Dimensional Entraining Detraining Plume Model and Its Application, J. Atmos. Sci., 47, 2784-2802, doi:10.1175/1520-0469(1990)047<2784:AODEPM>2.0.CO;2, 1990.

Skamarock, W. C., Klemp, J. B., Dudhia, J., Gill, D. O., Barker, D. M., Duda, M. G., Huang, X.-Y., Wang, W., and Powers, J. G.: A Description of the Advanced Research WRF Version 3, NCAR technical note, 2008.

Wald, L., Ranchin, T., and Mangolini, M.: Fusion of satellite images of different spatial resolutions: Assessing the quality of resulting images, Photogramm. Eng. Remote Sens., 63, 691-699, 1997. 